\title{
Effect of Bariatric Surgery on Weight Loss, Nutritional Deficiencies, Postoperative Complications and Adherence to Dietary and Lifestyle Recommendations \\ A retrospective cohort study from Bahrain
}

"Nawal A. Hasan, ${ }^{1}$ Afnan Freije, ${ }^{1}$ Abdulmenem Abualsel, ${ }^{2}$ Hani Al-Saati, ${ }^{3}$ Simone Perna ${ }^{1}$

$$
\begin{aligned}
& \text { تأثير جراحة السمنة على إنقاص الوزن ونقص التغذية ومضاعفات ما بعد } \\
& \text { الجراحة والالتزام بالنظام الغذائي ونمط الحياة } \\
& \text { دراسة استعادية جماعية من البحرين }
\end{aligned}
$$

نوال عبد الله حسن، أفنان فريجة، عبد المنعم أبو السل، هـاني الساعاتي، سيمون بيرنا

ABSTRACT: Objectives: This study aimed to investigate the effect of bariatric surgery on degree of weight loss, as well as the prevalence of nutritional deficiencies, postoperative complications and adherence to dietary and lifestyle recommendations in a cohort of patients from Bahrain. Methods: This retrospective cohort study took place between March and September 2018 at two hospitals in Bahrain. All adult patients who had undergone bariatric surgery between 2012-2017 were included. Sociodemographic and clinical information was collected from the patients' medical records and during phone interviews. Results: A total of 341 patients participated in the study. The mean age was $39.82 \pm 9.95$ years and $67.7 \%$ were female. There was a significant relationship between postoperative body mass index and both the type of surgery and time since surgery $(P=0.025$ and 0.008 , respectively). While type of surgery had no significant effect on percent of excess weight loss (EWL) or percent of total weight loss (TWL), time since surgery significantly affected both of these weight loss measures $(P=0.006$ and 0.001 , respectively). Biochemical tests revealed haemoglobin, mean corpuscular volume, 25-hydroxy vitamin D, ferritin and iron deficiencies. Commonly reported complications included hair loss (59.5\%), flatulence/abdominal pain (39.3\%), dry skin (34.3\%) and gastroesophageal reflux disease (33.1\%). The level of adherence to dietary and lifestyle recommendations was high to moderate. Conclusion: Bariatric surgery was effective in accelerating EWL and TWL; however, it also resulted in complications such as nutritional deficiencies and gastrointestinal side-effects.

Keywords: Bariatric Surgery; Obesity Management; Weight Loss; Gastric Bypass; Biliopancreatic Diversion; Avitaminosis; Iron-Deficiency Anemia; Bahrain.

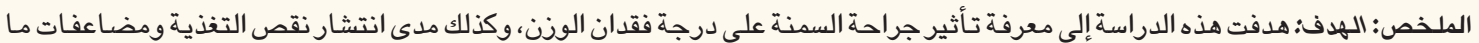

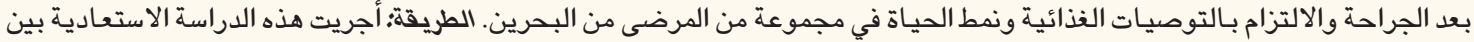

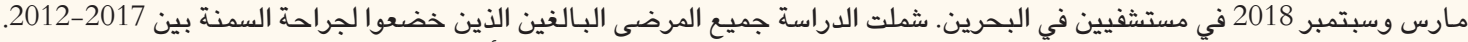

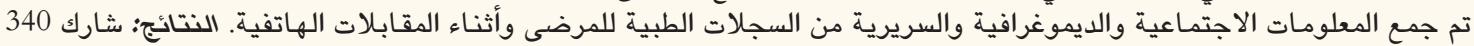

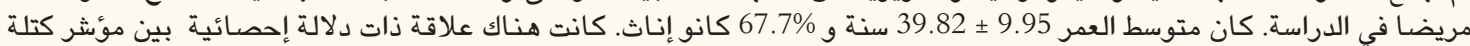

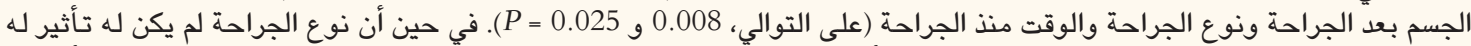

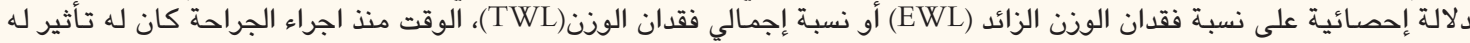

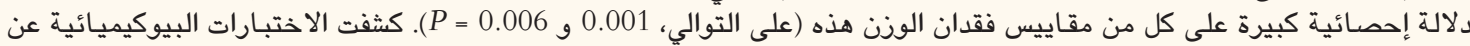

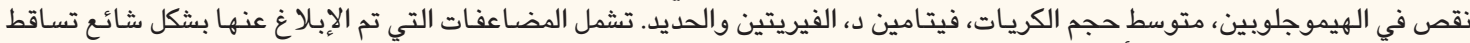

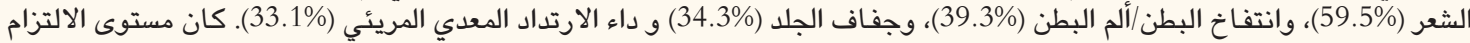

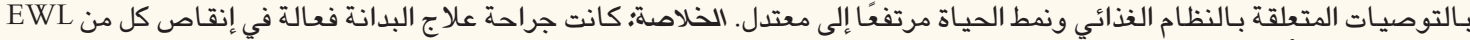
و و ولكنها أدت كذلك إلى حدوث مضاعفات مثل نقص التغذية والآثار الجانبية المعوية. الكلمات المفتاحية؛ جراحة السمنة؛ معالجة السمنة؛ فقدان الوزن؛ تحويل مسار المعدة؛ تحويل مسار البنكرياس؛ نقص الفيتامينات؛ فقر الدم بسبب نقصان الحديد؛ البحرين. 


\section{AdVANCES IN KNOWLEDGE}

Given the high rate of obesity in Bahrain, there is a need for evidence-backed research to support modalities for obesity management. This study confirms the effectiveness of bariatric surgery in reducing both percent of excess weight loss and total weight loss among a cohort of patients in Bahrain.

However, the rate of certain nutritional complications was concerning, particularly with regards to deficiencies in iron, haemoglobin and mean corpuscular volume, all of which are indicators of anaemia.

\section{Application to Patient Care}

The findings of this study indicate that patients require nutritional counselling to sustain weight loss outcomes and reduce rates of nutritional deficiencies and gastrointestinal side-effects following bariatric surgery.

\section{$\mathrm{T}$} HE CURRENT OBESITY EPIDEMIC IS A MAJOR public health problem in both developing and developed countries; according to global estimates, the prevalence of this disease doubled between 1980 and 2016, with approximately 13\% of all adults worldwide considered obese in 2014. ${ }^{1}$ According to the World Health Organization, obesity is defined as the accumulation of excessive fat in the body resulting in multiple adverse health effects including an increased risk of developing type 2 diabetes mellitus, cardiovascular diseases, coronary artery disease, hypertension, dyslipidaemia and obstructive sleep apnoea. ${ }^{2}$ In particular, Bahrain is considered one of the countries with the highest prevalence rates of obesity in the world. ${ }^{3}$ In 2007, nutritional surveillance indicated that the prevalence of obesity was $34.1 \%$ and $40.3 \%$ among males and females, respectively. These findings prompted the establishment of obesity clinics in 2008 to support and motivate patients to lose weight. ${ }^{5}$

Currently, bariatric surgery is considered the most effective treatment option to reduce morbidity and mortality in morbidly obese patients (i.e. those with body mass indexes [BMIs] of $\left.\geq 40 \mathrm{~kg} / \mathrm{m}^{2}\right)^{6}{ }^{6}$ According to the 1991 consensus guidelines of the National Institutes of Health in the USA, eligible patients for this type of surgery should have either a BMI of $>40 \mathrm{~kg} / \mathrm{m}^{2}$ or a BMI of $35-40 \mathrm{~kg} / \mathrm{m}^{2}$ along with an obesity-related disease such as diabetes, hypertension or cardiovascular diseases. ${ }^{7}$ Worldwide, the three most common types of bariatric surgery are sleeve gastrectomy (SG), mini gastric bypass (MGB) and Roux-en-Y gastric bypass (RYGB). ${ }^{8}$

Patients may develop gastrointestinal complications following bariatric surgery including nausea, vomiting, constipation, diarrhoea, regurgitation, dumping syndrome and decreased appetite. ${ }^{9,10}$ Moreover, depending on the type of procedure, behavioural alterations in eating patterns and anatomical and physiological modifications to the gastrointestinal organs can result in significant protein and micronutrient deficiencies such as thiamine (vitamin B1), cobalamin (vitamin B12), folate, calcium and vitamin $\mathrm{D}$ deficiencies. ${ }^{9,11}$ These can be exacerbated by nonadherence on the part of the patient in taking necessary supplements. ${ }^{12,13}$

This study aimed to measure the effectiveness of bariatric surgery in reducing weight as well as the level of adherence to dietary and lifestyle recommendations and prevalence of nutritional deficiencies and selfreported complications among a cohort of patients in Bahrain. Moreover, the study aimed to determine the relationship between weight loss and nutritional parameters with type of surgery, time since surgery and sociodemographic characteristics.

\section{Methods}

This retrospective cohort study was conducted between March and September 2018 at the King Hamad University Hospital (KHUH) and Salmaniya Medical Complex (SMC) in Bahrain. All patients between 18-65 years of age and who had undergone bariatric surgery between one and six years previously (i.e. between 2012 and 2017) were included in the study. All bariatric surgery candidates met the National Institutes of Health criteria with regards to their eligibility for surgical intervention. ${ }^{7}$ However, patients who had undergone the surgery less than one year previously and pregnant women were excluded, as were patients who had undergone revisional bariatric surgery since the initial procedure.

The physical parameters of the patients were measured in line with the outcome reporting standards of the American Society for Metabolic and Bariatric Surgery. ${ }^{14}$ As such, weight in kg and height in $\mathrm{m}$ were measured on a digital medical scale, with BMI calculated by dividing weight by height squared. ${ }^{1,2}$ Subsequently, percent of excess weight loss (EWL) and percent of total weight loss (TWL) were calculated according to the below formulae, ${ }^{14}$ with ideal BMI defined as $25 \mathrm{~kg} / \mathrm{m}^{2}$ :

$$
\begin{aligned}
& \mathrm{EWL}=\frac{\text { preoperative BMI-postoperative BMI }}{\text { preoperative BMI-ideal BMI }} \times 100 \\
& \mathrm{TWL}=\frac{\text { preoperative weight-postoperative weight }}{\text { preoperative weight }} \times 100
\end{aligned}
$$


Blood samples were collected during routine analysis between 8 AM and 10 PM following a 12hour fasting interval and then analysed based on the standard laboratory protocols of the participating hospitals. Nutritional deficiencies were identified by reviewing and comparing various nutritional parameters with normal reference ranges of calcium, 25-hydroxy $(\mathrm{OH})$ vitamin $\mathrm{D}$, vitamin $\mathrm{B} 12$, iron, ferritin, haemoglobin, haematocrit, mean corpuscular volume (MCV), cholesterol, sodium, potassium and magnesium. ${ }^{15}$

A questionnaire was developed in both Arabic and English to collect data from the participants. The questionnaire was divided into three parts, in which the first assessed demographic data and the second investigated if the participant was currently experiencing any complications which had appeared postoperatively (i.e. dehydration, constipation, hair loss, etc.). The third part was based on previously published work by Mechanick et al. and assessed the level of adherence to important post-surgery dietary and lifestyle recommendations. ${ }^{11}$ In this section, participants rated their frequency of adherence to each recommendation as either all of the time, most of the time, some of the time or rarely/never. The full questionnaire was pilot-tested on 13 adults who had also undergone bariatric surgery, although not necessarily at KHUH or SMC. Subsequently, the final version of the questionnaire was completed during phone interviews with the patients. In each case, a total of five attempts were made to reach patients by phone; if patients were unreachable or not interested in completing the questionnaire, only their biochemistry tests were reviewed and including in the analysis.

Data were entered into an Excel spreadsheet, Version 2010 (Microsoft Corp., Redmond, Washington, USA) and analysed using the Statistical
Package for the Social Sciences (SPSS), Version 23.0 (IBM Corp., Armonk, New York, USA). Descriptive results were presented as either frequencies and percentages or means and standard deviations. A repeated measures analysis of variance analysis was used to evaluate the effect of type of surgery and time since surgery on preoperative and postoperative BMI, after adjusting for age, gender and time or type of surgery. Differences in EWL and TWL between surgery types and time intervals were compared utilising an analysis of covariance model, after adjusting for the appropriate covariates. Adherence to dietary and lifestyle recommendations was classified as responses of "all of the time" or "most of the time" to each recommendation while nonadherence was classified by responses of "some of the time" or "rarely/ never". Categorical data regarding the differences between surgeries were tested using a Pearson's Chi-square test. A two-sided $P$ value of $<0.050$ was considered statistically significant.

Permission to conduct this study was obtained from the Education and Proficiency Centre and Research and Ethics Committee of KHUH (KHUH/ Research/No. 211/2018) as well as from the Health Research Committee of the Ministry of Health in Bahrain (AUHR/ 498/2018). All procedures were conducted in accordance with the ethical standards of the revised Declaration of Helsinki. Informed consent was obtained from all participants included in the study.

\section{Results}

Overall, 396 patients were scheduled for bariatric surgery between 2012 and 2017 including 183 patients (46.2\%) from $\mathrm{KHUH}$ and 213 (53.8\%) from SMC; however, 56 patients $(14.1 \%)$ were excluded for

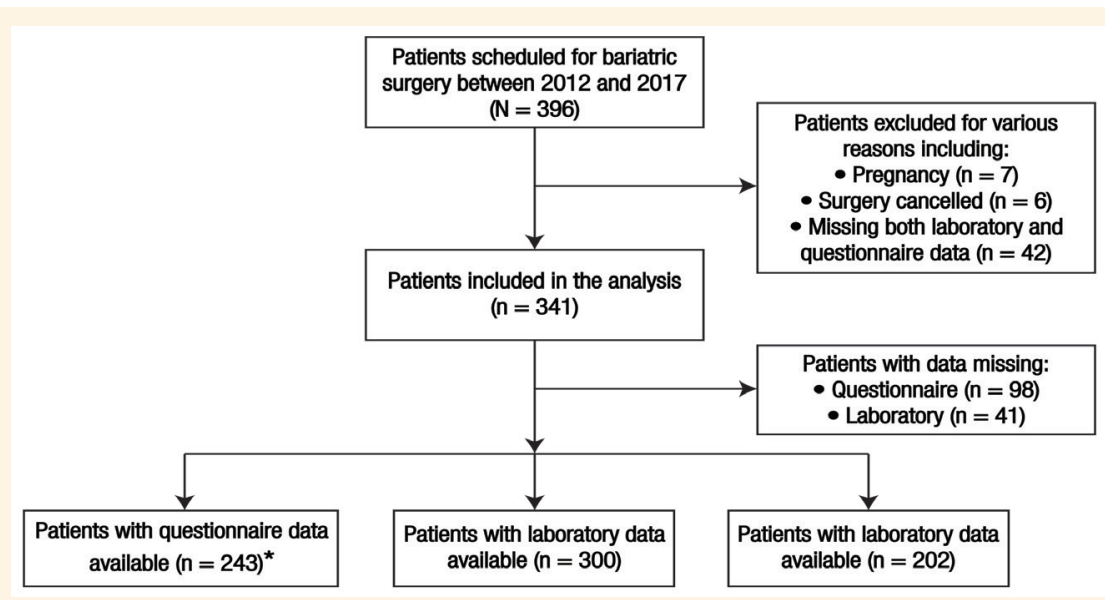

Figure 1: Flowchart showing the inclusion and allocation of patients in the current study.

"One patient participated in the study and completed the questionnaire but was later excluded because she was the only patient who underwent adjustable gastric band surgery. Therefore, for statistical reasons, this patient was excluded leaving 242 total patients. 
Table 1: Sociodemographic and clinical characteristics of bariatric surgery patients in Bahrain $(\mathrm{N}=340)$

\begin{tabular}{|c|c|}
\hline Characteristic & n (\%) \\
\hline Mean age in years $\pm S D$ & $39.82 \pm 9.95$ \\
\hline \multicolumn{2}{|l|}{ Gender } \\
\hline Male & $110(32.4)$ \\
\hline Female & $230(67.6)$ \\
\hline \multicolumn{2}{|l|}{ Nationality } \\
\hline Bahraini & $318(93.5)$ \\
\hline Non-Bahraini & $22(6.5)$ \\
\hline \multicolumn{2}{|l|}{ Education level* } \\
\hline Primary & $5(2.1)$ \\
\hline Intermediate & $17(7.1)$ \\
\hline Secondary & $103(42.7)$ \\
\hline Diploma/BSc & $99(41.1)$ \\
\hline Postgraduate & $17(7.1)$ \\
\hline \multicolumn{2}{|l|}{ Marital status* } \\
\hline Single & $65(26.9)$ \\
\hline Married & $177(73.1)$ \\
\hline \multicolumn{2}{|c|}{ Time since surgery in years } \\
\hline 1 & $104(30.6)$ \\
\hline 2 & 84. (24.7) \\
\hline 3 & $24(7.1)$ \\
\hline 4 & $59(17.4)$ \\
\hline 5 & $61(17.9)$ \\
\hline 6 & $8(2.4)$ \\
\hline \multicolumn{2}{|l|}{ Type of surgery } \\
\hline SG & $191(57.9)$ \\
\hline $\mathrm{BPD}$ & $34(10.3)$ \\
\hline MGB & $105(31.8)$ \\
\hline \multicolumn{2}{|l|}{ Mean $\mathrm{BMI} \pm \mathrm{SD}$ in $\mathrm{kg} / \mathrm{m}^{2}$} \\
\hline Preoperative/baseline & $48.16 \pm 9.25$ \\
\hline Postoperative/current & $30.16 \pm 5.97$ \\
\hline \multicolumn{2}{|c|}{$\begin{array}{l}S D=\text { standard deviation; } B S C=\text { Bachelor of Science; } S G=\text { sleeve gastrectom } \\
B P D=\text { biliopancreatic diversion; } M G B=\text { mini gastric bypass; } B M I=\text { bod } \\
\text { mass index. "Percentages for this variable are calculated out of } 242 \text {, a } \\
99 \text { patients were unreachable by telephone or did not wish to complet } \\
\text { the questionnaire. }\end{array}$} \\
\hline
\end{tabular}

various reasons. As such, a total of 340 patients $(85.9$ $\%)$ were included in the final analysis [Figure 1]. The mean age of the participants was $39.82 \pm 9.95$ years and over two-thirds were female (67.6\%). The majority were of Bahraini nationality (93.5\%) and married (73.1\%). A total of 103 patients (42.7\%) were educated to the secondary school level. The most common type of bariatric surgery was SG (57.9\%) followed by MGB (31.8\%) and biliopancreatic diversion (BPD; 10.3\%). Approximately one-third of the patients (30.6\%) had undergone bariatric surgery one year previously. Mean BMI values at baseline and following bariatric surgery were $48.16 \pm 9.25$ and $30.16 \pm 5.97 \mathrm{~kg} / \mathrm{m}^{2}$, respectively [Table 1].

With regards to surgery type, patients who underwent BPD had the highest mean BMI values, both at baseline and after the surgery (56.76 and $34.81 \mathrm{~kg} /$ $\mathrm{m}^{2}$, respectively). While patients who underwent SG and MGB had similar preoperative BMI values (47.23 and $47.58 \mathrm{~kg} / \mathrm{m}^{2}$, respectively), MGB patients had the lowest postoperative BMI value among all surgery types $\left(28.60 \mathrm{~kg} / \mathrm{m}^{2}\right)$. In terms of time since surgery, patients who had undergone surgery six years previously had the highest mean BMI values, both at baseline and after the surgery 56.76 and $34.81 \mathrm{~kg} / \mathrm{m}^{2}$, respectively. In contrast, the lowest mean postoperative BMI was reported in patients who have undergone the surgery three years previously $\left(26.98 \mathrm{~kg} / \mathrm{m}^{2}\right)$. Both surgery type and time since surgery had a significant effect on BMI reduction $(P=0.025$ and 0.008 , respectively) [Figure 2]. Moreover, there was a significant association between time since surgery and both EWL and TWL ( $P=0.006$ and 0.001 , respectively) [Figure 3]. With regards to sociodemographic characteristics, age and gender were significantly associated with TWL $(P=$ 0.029 and 0.008 , respectively), but not EWL.

An investigation of the nutritional status of the patients revealed that the majority had normal levels of most of the assessed indicators. However, almost half of the patients had iron, MCV and haemoglobin deficiencies ( $48.7 \%, 47.0 \%$ and $46.7 \%$, respectively). Moreover, $40 \%$ and $41.3 \%$ had $25-\mathrm{OH}$ vitamin D insufficiency and deficiency, respectively. In addition, $38 \%$ of patients were deficient in ferritin. After controlling for covariates like age, gender and time of surgery, type of surgery was only found to have a significant effect on cholesterol $(P<0.001)$. On the other hand, time of surgery had a significant effect on multiple nutritional parameters, including sodium $(P$ $<0.001)$, potassium $(P<0.001)$, albumin $(P<0.001)$, calcium $(P<0.050)$, vitamin B12 $(P<0.010)$ and haemoglobin $(P<0.010)$.

Certain postoperative complications were reported by the patients, with the most common being hair loss (59.5\%) followed by flatulence/abdominal pain (39.3\%), dry skin (34.3\%) and gastroesophageal reflux disease (33.1\%). Significant differences were observed between the different types of surgery in terms of the rates of constipation, diarrhoea, flatulence/abdominal pain, anaemia, hypoglycaemia, cholelithiasis and fatigue $(P \leq 0.050$ each) [Table 2]. With regards to 
A

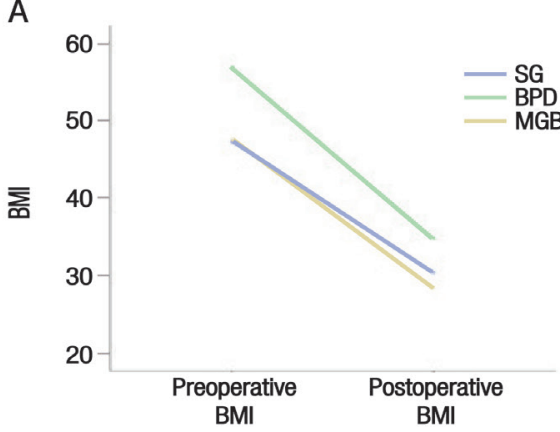

B

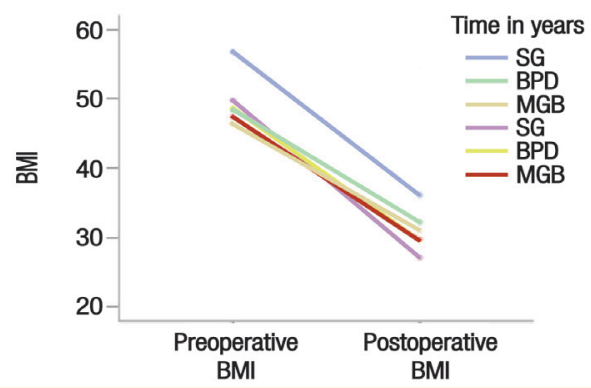

Figure 2: Difference in reduction in preoperative and postoperative body mass index according to (A) type of surgery $(P=0.025)^{*}$ and $(B)$ time since surgery $(P=0.008)^{\dagger}$ among bariatric surgery patients in Bahrain $(\mathrm{N}=341)$.

$B M I=$ body mass index; $S G$ = sleeve gastrectomy; $B P D=$ biliopancreatic diversion; $M G B=$ mini gastric bypass. "Covariates were adjusted for age, gender and time since surgery. ${ }^{\dagger}$ Covariates were adjusted for age, gender and type of surgery.

A

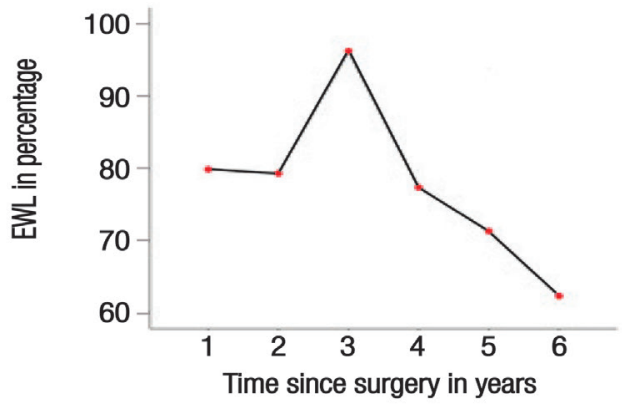

B

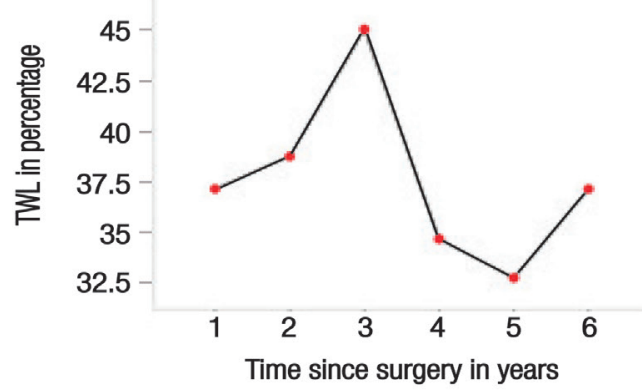

Figure 3: Effect of time since surgery on (A) percent of excess weight loss $(P=0.006) *$ and $(\mathrm{B})$ percent of total weight loss $(P=$ $0.001)^{*}$ among bariatric surgery patients in Bahrain $(\mathrm{N}=341)$.

$E W L=$ percent of excess weight loss; $T W L=$ percent of total weight loss. "Covariates were adjusted for age, gender and type of surgery.

Table 2: Frequency of self-reported postoperative complications according to type of surgery among bariatric surgery patients in Bahrain $(\mathrm{N}=242)$

\begin{tabular}{|c|c|c|c|c|c|c|}
\hline \multirow[t]{2}{*}{ Complication } & \multicolumn{4}{|c|}{ n (\%) } & \multirow[t]{2}{*}{$x^{2}$} & \multirow[t]{2}{*}{$P$ value } \\
\hline & Total $*$ & SG & BPD & MGB & & \\
\hline Dry skin & $83(34.3)$ & $45(54.2)$ & $10(12)$ & $28(33.7)$ & 8.081 & 0.232 \\
\hline Constipation & $66(27.3)$ & $46(69.7)$ & $2(3)$ & $18(27.3)$ & 21.777 & 0.001 \\
\hline Diarrhoea & $50(20.7)$ & $10(20.0)$ & $15(30.0)$ & $25(50)$ & 58.306 & $<0.001$ \\
\hline Dysphagia & $25(10.3)$ & $15(60)$ & $0(0)$ & $10(40)$ & 6.150 & 0.407 \\
\hline Low appetite & $65(26.9)$ & $38(58.5)$ & $3(4.6)$ & $24(36.9)$ & 5.947 & 0.429 \\
\hline Hair loss & $144(59.5)$ & $85(59.0)$ & $8(5.6)$ & $51(35.4)$ & 9.766 & 0.135 \\
\hline Flatulence/ abdominal pain & $95(39.3)$ & $43(45.3)$ & $13(13.7)$ & $39(41.4)$ & 14.787 & 0.022 \\
\hline Anaemia & $64(26.4)$ & $24(37.5)$ & $11(17.2)$ & $29(45.3)$ & 19.841 & 0.003 \\
\hline Hypotension & $61(25.2)$ & $31(50.8)$ & $6(9.8)$ & $24(39.3)$ & 5.435 & 0.489 \\
\hline Hypoglycaemia & $48(19.8)$ & $21(43.8)$ & $3(6.3)$ & $24(50)$ & 12.628 & 0.049 \\
\hline Lactose intolerance & $32(13.2)$ & $12(37.5)$ & $6(18.8)$ & $14(43.8)$ & 11.012 & 0.088 \\
\hline GERD & $80(33.1)$ & $44(55.0)$ & $5(6.3)$ & $31(38.8)$ & 8.309 & 0.216 \\
\hline Cholelithiasis & 33 (13.6) & $10(30.3)$ & $11(33.3)$ & $12(36.4)$ & 31.883 & $<0.001$ \\
\hline Fatigue & $44(18.2)$ & $12(27.3)$ & $4(9.1)$ & $28(63.6)$ & 28.415 & $<0.001$ \\
\hline
\end{tabular}

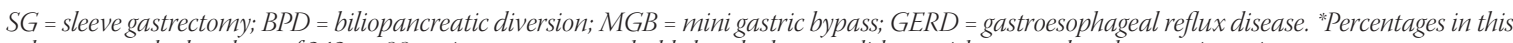
column are calculated out of 242, as 99 patients were unreachable by telephone or did not wish to complete the questionnaire. 
Table 3: Adherence to dietary and lifestyle recommendations among bariatric surgery patients in Bahrain $(\mathrm{N}=242)$

\begin{tabular}{|c|c|c|c|c|}
\hline \multirow[t]{2}{*}{ Recommendation } & \multicolumn{4}{|c|}{ Level of adherence, $\mathbf{n}(\%)^{*}$} \\
\hline & All of the time & $\begin{array}{l}\text { Most of the } \\
\text { time }\end{array}$ & $\begin{array}{l}\text { Some of the } \\
\text { time }\end{array}$ & Never/rarely \\
\hline Eat $4-5$ meals a day (three main meals and $1-2$ snacks) & $72(29.8)$ & $80(33.1)$ & 64. (26.4) & $26(10.7)$ \\
\hline Eat and chew food slowly & $97(40.1)$ & $63(26)$ & $49(20.2)$ & $33(13.6)$ \\
\hline Control portion size and try not to overeat & $153(63.2)$ & $42(17.4)$ & $33(13.6)$ & $14(5.8)$ \\
\hline $\begin{array}{l}\text { Avoid eating high-calorie snacks (i.e. milkshakes, sugary } \\
\text { juices, ice cream, chocolate, crisps, cookies, etc.) }\end{array}$ & $50(20.7)$ & $61(25.2)$ & $58(24)$ & $73(30.2)$ \\
\hline Avoid eating and drinking at the same time & $156(64.5)$ & $29(12)$ & $29(12)$ & $28(11.6)$ \\
\hline Take recommended vitamin and mineral supplements & $91(37.6)$ & $28(11.6)$ & $66(27.3)$ & $57(23.6)$ \\
\hline Exercise at least three times a week & $62(25.6)$ & $35(14.5)$ & $61(25.2)$ & $84(34.7)$ \\
\hline $\begin{array}{l}\text { Attend follow-up appointments with a doctor and do all } \\
\text { required tests }\end{array}$ & $139(57.4)$ & $25(10.3)$ & $33(13.6)$ & $45(18.6)$ \\
\hline
\end{tabular}

*Percentages are calculated out of 242, as 99 patients were unreachable by telephone or did not wish to complete the questionnaire.

dietary and lifestyle recommendations, participants most frequently adhered to the recommendation that they avoid overeating and controlling the portion size $(80.6 \%)$. On the other hand, participants least frequently adhered to recommendations to exercise at least three times a week (59.9\%) and avoid eating highcalorie snacks (54.2\%) [Table 3].

\section{Discussion}

This study sought to assess the effectiveness of bariatric surgery in reducing weight as well as the prevalence of nutritional deficiencies and selfreported complications and level of adherence to dietary and lifestyle recommendations among patients in Bahrain. Overall, the primary objectives of bariatric surgery are weight loss and the resolution of obesity-related diseases. ${ }^{6,8} 9$ Studies evaluating the efficacy of bariatric surgery have found that effect on weight loss-as determined by EWL-depends on the type of procedure performed with adjustable gastric band (AGB) surgery reportedly being least effective compared to RYGB and SG. ${ }^{9,16-18}$ However, most previous research focuses on comparing weight loss between RYGB, MGB and SG, since other types of bariatric surgeries such as AGB and BPD are no longer commonly performed. ${ }^{7}$ In the current study, most patients underwent either SG or MGB; however, a minority (10.3\%) had undergone BPD approximately 5-6 years prior to the study period.

In the present study, time since surgery had a significant effect on TWL and EWL, but not type of surgery. In contrast, other researchers have found that patients who underwent malabsorptive or combined restrictive-malabsorptive procedures (i.e. BPD, RYGB and MGB) lost more excess weight compared to those who underwent purely restrictive procedures (i.e. SG and AGB). ${ }^{19}$ However, in the current study, the lowest mean postoperative BMI value was observed among patients who had MGB but not BPD. This may be because most BPD patients had undergone surgery between 5-6 years previously, the longest postoperative time interval assessed in the study.

Unfortunately, the majority of patients in the current study who had undergone bariatric surgery more than five years previously were once more obese at the time of assessment. Many studies have highlighted the failure to maintain weight loss over time following bariatric surgery and the tendency to regain the weight within two to three years. ${ }^{10,20}$ The prevalence of weight regain among bariatric surgery patients has been found to depend on surgery type, with greater weight regain identified in patients undergoing AGB compared to RYGB (35-40\% versus $7-50 \%$ weight regained). ${ }^{21,22}$ Length of follow-up may also play a role; a recent review by Lauti et al. revealing that rates of weight regain after SG ranged from 5.7\% two years following the surgery to $75.6 \%$ six years later. $^{10}$

While studies have shown that nutritional deficiencies are usually prevalent beforehand in obese patients, bariatric surgery may exacerbate the problem and/or introduce new deficiencies. ${ }^{15,23,24}$ According to a biochemical assessment of various nutritional parameters, approximately half of the patients in the current study were deficient in iron, haemoglobin and $\mathrm{MCV}$, all of which are indicators of anaemia. A recent review article reported iron deficiency to be the most common nutritional deficiency following bariatric surgery. ${ }^{25}$ However, the rate of $25-\mathrm{OH}$ vitamin D insufficiency and deficiency was moderate. Research shows that hypovitaminosis D is already present 
preoperatively in a significant number of bariatric surgery patients (25-80\%). ${ }^{26}$ Reasons for this include low consumption of vitamin D-rich foods, reduced sun exposure and the decreased bioavailability of vitamin D in obese patients due to its being deposited in adipose tissue. ${ }^{27}$

Certain gastrointestinal symptoms and nutritional complaints may arise after bariatric surgery, potentially influencing the patient's quality of life. ${ }^{9,16}$ Among these, hair loss is one of the most commonly reported and is related to rapid weight loss and deficiencies of iron, zinc and other micronutrients. ${ }^{28}$ In the present study, the prevalence of hair loss was $59.5 \%$, a rate which is in line with that reported by other researchers (4060\%); however, Goldenshluger et al. observed a greater frequency of hair loss in MGB patients compared to those who underwent SG, while the opposite was true in the present study. ${ }^{29}$ This may be related to the higher number of SG patients included in the current study and the fact that $55.3 \%$ had undergone the surgery between 1-2 years previously, a time when weight loss is commonly rapid in bariatric surgery patients. ${ }^{30}$ In turn, hypoglycaemia was recorded in under a quarter of the respondents in the present study. This condition has not yet been sufficiently studied in bariatric surgery populations, although it is frequently identified in patients with dumping syndrome. ${ }^{29}$ According to Lin et al., the risk of hypoglycaemia is increased 2-7-fold in postoperative gastric bypass patients. ${ }^{31} \mathrm{~A}$ similar finding was observed in the current study in that $50 \%$ of patients who developed hypoglycaemia had undergone MGB surgery.

Adherence to dietary and lifestyle recommendations is critical to the long-term health and weight outcomes of patients who undergo bariatric surgery. ${ }^{9,32,33}$ In the present study, the patients reported medium to high adherence to such recommendations. This could be due to the fact that $30.6 \%$ of the patients had recently undergone the surgery one year before the study took place. According to research, the period both prior to surgery and immediately afterwards is when patients demonstrate the greatest adherence to dietary and lifestyle advice; however, as time progress, the rate of adherence decreases. ${ }^{31,32}$ In particular, patients in the present study were least adherent to the recommendation that they avoid high-calorie snacks (i.e. milkshakes, sugary juices, ice cream, chocolate, crisps, cookies, etc.), a choice which could have a considerable impact on their weight and general health.

The current study has several strengths and limitations. In particular, the large number of patients included in the study as well as the fact that they were recruited from two of the three main governmental hospitals in Bahrain can be considered strengths. In terms of limitations, the study was constrained by its retrospective nature. The weight of the patients was assessed only once at the time of the study and then compared to existing preoperative data in their medical records. It may have been better to measure weight prospectively at several time intervals in order to determine the overall trend of weight loss and identify the exact point in time at which the patients began to regain weight. Secondly, biochemical parameters for nutritional indicators were assessed only postoperatively at the time of the study, so it was not possible to confirm the exact cause of nutritional deficiencies. Finally, data regarding the prevalence of postoperative complications and level of adherence to dietary and lifestyle recommendations were selfreported by the participants; this may have introduced response bias.

\section{Conclusion}

The findings of this study confirm that bariatric surgery is an effective intervention in obesity treatment in terms of weight loss measures such as EWL and TWL. However, it also resulted in postoperative complications as well as the possible development of nutritional deficiencies. Such complications can be controlled by adhering to postoperative recommendations. Patients should be aware that bariatric surgery alone is not a miracle cure to weight loss and that there is a need for them to maintain the recommended dietary and lifestyle behaviours that they practiced prior to the surgery.

\section{CONFLICT OF INTEREST}

The authors declare no conflicts of interest.

\section{FUNDING}

No funding was received for this study.

\section{References}

1. World Health Organization. Fact sheets: Obesity and overweight. From: www.who.int/news-room/fact-sheets/ detail/obesity-and-overweight Accessed: Feb 2020.

2. World Health Organization. Health topics: Obesity. From: www.who.int/topics/obesity/en/ Accessed: Feb 2020.

3. Dillinger J. World atlas: The most obese countries in the world. From: www.worldatlas.com/articles/29-most-obese-countriesin-the-world.html Accessed: Feb 2020.

4. Bahrain Ministry of Health. National non-communicable diseases risk factor survey 2007. From: www.who.int/ ncds/surveillance/steps/2007_STEPS_Survey_Bahrain.pdf Accessed: Feb 2020. 
5. World Health Organization. Nutrition clinics help tackle obesity in Bahrain. From: www.who.int/features/2014/bahraintackle-obesity/en/ Accessed: Feb 2020.

6. Sjöström L. Review of the key results from the Swedish Obese Subjects (SOS) trial: A prospective controlled intervention study of bariatric surgery. J Intern Med 2013; 273:219-34. https://doi.org/10.1111/joim.12012.

7. National Institutes of Health. NIH conference: Gastrointestinal surgery for severe obesity - Consensus development conference panel. Ann Intern Med 1991; 115:956-61. https://doi.org/10.7 326/0003-4819-115-12-956.

8. Himpens J, Ramos A, Welbourn R, Dixon J, Kinsman R, Walton P. The International Federation for the Surgery of Obesity and Metabolic Disorders global registry: 4th IFSO global registry report. From: www.ifso.com/pdf/4th-ifso-global-registry-repo rt-last-2018.pdf Accessed: Feb 2020.

9. Brethauer SA, Chand B, Schauer PR. Risks and benefits of bariatric surgery: Current evidence. Cleve Clin J Med 2006; 73:993-1007. https://doi.org/10.3949/ccjm.73.11.993.

10. Lauti M, Kularatna M, Hill AG, MacCormick AD. Weight regain following sleeve gastrectomy: A systematic review. Obes Surg 2016; 26:1326-34. https://doi.org/10.1007/s11695-0162152-x.

11. Mechanick JI, Youdim A, Jones DB, Garvey WT, Hurley DL, McMahon MM, et al. Clinical practice guidelines for the perioperative nutritional, metabolic, and nonsurgical support of the bariatric surgery patient: 2013 update - Cosponsored by American Association of Clinical Endocrinologists, the Obesity Society, and American Society for Metabolic \& Bariatric Surgery. Obesity (Silver Spring) 2013; 21:S1-27. https://doi. org/10.1002/oby.20461.

12. Schweiger C, Weiss R, Berry E, Keidar A. Nutritional deficiencies in bariatric surgery candidates. Obes Surg 2010; 20:193-7. https://doi.org/10.1007/s11695-009-0008-3.

13. Nicoletti CF, Lima TP, Donadelli SP, Salgado W Jr, Marchini JS, Nonino CB. New look at nutritional care for obese patient candidates for bariatric surgery. Surg Obes Relat Dis 2013; 9:520-5. https://doi.org/10.1016/j.soard.2011.08.010.

14. Brethauer SA, Kim J, el Chaar M, Papasavas P, Eisenberg D, Rogers A, et al. Standardized outcomes reporting in metabolic and bariatric surgery. Surg Obes Relat Dis 2015; 11:489-506. https://doi.org/10.1016/j.soard.2015.02.003.

15. Al-Mutawa A, Anderson AK, Alsabah S, Al-Mutawa M Nutritional status of bariatric surgery candidates. Nutrients 2018; 10:67. https://doi.org/10.3390/nu10010067.

16. Chang SH, Stoll CR, Song J, Varela JE, Eagon CJ, Colditz GA, et al. The effectiveness and risks of bariatric surgery: An updated systematic review and meta-analysis, 2003-2012. JAMA Surg 2014; 149:275-87. https://doi.org/10.1001/jamasurg.2013.3654.

17. Schauer PR, Burguera B, Ikramuddin S, Cottam D, Gourash W, Hamad G, et al. Effect of laparoscopic Roux-en Y gastric bypass on type 2 diabetes mellitus. Ann Surg 2003; 238:467-85. https://doi.org/10.1097/01.sla.0000089851.41115.1b.

18. Pournaras DJ, Osborne A, Hawkins SC, Vincent RP, Mahon D, Ewings $\mathrm{P}$, et al. Remission of type 2 diabetes after gastric bypass and banding: Mechanisms and 2 year outcomes. Ann Surg 2010; 252:966-71. https://doi.org/10.1097/SLA.0b013e3181efc49a.

19. Nasta AM, Goel R, Dharia S, Goel M, Hamrapurkar S. Weight loss and comorbidity resolution 3 years after bariatric surgery: An Indian perspective. Obes Surg 2018; 28:2712-19. https:// doi.org/10.1007/s11695-018-3218-8.
20. Karmali S, Brar B, Shi X, Sharma AM, de Gara C, Birch DW. Weight recidivism post-bariatric surgery: A systematic review. Obes Surg 2013; 23:1922-33. https://doi.org/10.1007/s11695013-1070-4.

21. DiGiorgi M. Factors associated with long term weight regain after bariatric surgery. Ph.D. Thesis, 2012, Columbia University, New York, USA.

22. Magro DO, Geloneze B, Delfini R, Pareja BC, Callejas F, Pareja JC. Long-term weight regain after gastric bypass: A 5-year prospective study. Obes Surg 2008; 18:648-51. https://doi. org/10.1007/s11695-007-9265-1.

23. Xanthakos SA. Nutritional deficiencies in obesity and after bariatric surgery. Pediatr Clin North Am 2009; 56:1105-21. https://doi.org/10.1016/j.pcl.2009.07.002.

24. Billeter AT, Probst P, Fischer L, Senft J, Kenngott HG, Schulte T, et al. Risk of malnutrition, trace metal, and vitamin deficiency post Roux-en-Y gastric bypass: A prospective study of 20 patients with BMI $<35 \mathrm{~kg} / \mathrm{m} 2$. Obes Surg 2015; 25:2125-34. https://doi.org/10.1007/s11695-015-1676-9.

25. Patel JJ, Mundi MS, Hurt RT, Wolfe B, Martindale RG. Micronutrient deficiencies after bariatric surgery: An emphasis on vitamins and trace minerals. Nutr Clin Pract 2017; 32:471-80. https://doi.org/10.1177/0884533617712226.

26. Stein J, Stier C, Raab H, Weiner R. Review article: The nutritional and pharmacological consequences of obesity surgery. Aliment Pharmacol Ther 2014; 40:582-609. https://doi.org/10.1111/ apt.12872.

27. Stroth C, Manger T, Benedix F. Metabolic surgery and nutritional deficiencies. Minerva Chir 2017; 72:432-41. https:// doi.org/10.23736/S0026-4733.17.07408-9.

28. Ruiz-Tovar J, Oller I, Llavero C, Zubiaga L, Diez M, Arroyo A, et al. Hair loss in females after sleeve gastrectomy: Predictive value of serum zinc and iron levels. Am Surg 2014; 80:466-71. https://doi.org/10.1177/000313481408000517.

29. Goldenshluger M, Goldenshluger A, Keinan-Boker L, Cohen MJ, Ben-Porat T, Gerasi H, et al. Postoperative outcomes, weight loss predictors, and late gastrointestinal symptoms following laparoscopic sleeve gastrectomy. I Gastrointest Surg 2017; 21:2009-15. https://doi.org/10.1007/s11605-017-3585-9.

30. Courcoulas A, Yanovsk S, Bonds D, Eggerman T, Horlick M, Staten M, et al. 2013. Weight Change and Health Outcomes at 3 Years after Bariatric Surgery among individuals with Severe Obesity. JAMA Surg 2014; 149:1323-9. https:/doi:10.1001/ jamasurg.2014.2440.

31. Lin S, Guan W, Yang N, Zang Y, Liu R, Liang H. Short-term outcomes of sleeve gastrectomy plus jejunojejunal bypass: A retrospective comparative study with sleeve gastrectomy and Roux-en-Y gastric bypass in Chinese patients with BMI $\geq 35$ kg/m2. Obes Surg 2019; 29:1352-9. https://doi.org/10.1007/ s11695-018-03688-1.

32. Handzlik-Orlik G, Holecki M, Orlik B, Wyleżoł M, Duława J. Nutrition management of the post-bariatric surgery patient. Nutr Clin Pract 2015; 30:383-92. https://doi. org/10.1177/0884533614564995.

33. Larjani S, Spivak I, Guo MH, Aliarzadeh B, Wang W, Robinson S, et al. Preoperative predictors of adherence to multidisciplinary follow-up care postbariatric surgery. Surg Obes Relat Dis 2016; 12:350-6. https://doi.org/10.1016/j.soard.2015.11.007. 